\title{
Glass-ionomers have cariostatic effect
}

\author{
Is a glass-ionomer fissure sealant effective in reducing occlusal caries?
}

\author{
Pereira AC, Pardi V, Mialhe FL, Meneghim Mde C, Ambrosano \\ GM. A 3-year clinical evaluation of glass-ionomer cements used as \\ fissure sealants. Am J Dent 2003; 16:23-27
}

Design A randomised controlled trial (RCT) conducted over a period of 3 years.

Intervention Either conventional glass-ionomer (Ketac-bond; $3 \mathrm{M}$ ESPE St. Paul, MN 55144-1000) or resin-modified glass-ionomer (Vitremer; 3M ESPE St. Paul, MN 55144-1000) sealants were applied to first permanent molars, and oral hygiene education was given. Clinical evaluations were carried out at 6, 12, 24, and 36 months after the application of the sealant.

Outcome measure Retention rates and occlusal caries incidence were monitored.

Results The difference in retention rates between the two materials was statistically significant. The experimental groups showed a caries incidence of $93,78,49$, and $56 \%$ lower than the control group $(P<0.01)$ for the four evaluation periods, respectively (see Table 1$)$.

Conclusions The retention rates for glass-ionomer were low. Nevertheless, the statistically lower caries incidence in experimental groups compared with control group suggests a cariostatic effect.

Table 1. Retention rates and occlusal caries incidence.

\begin{tabular}{lrrrrrrr}
\hline & \multicolumn{2}{c}{ Retention rates $(n)$} & & \multicolumn{3}{c}{ Carious/filled occlusal surfaces $(n)$} \\
\cline { 2 - 3 } \cline { 5 - 7 } \cline { 5 - 7 } & Ketac-bond & Vitremer & & Ketac-bond & Vitremer & Control \\
\hline Patients $(n)$ & 50 & 50 & & 50 & 50 & 108 \\
Teeth at & 200 & 200 & & 200 & 200 & 432 \\
baseline $(n)$ & 12 & 31 & & 7 & 7 & 64 \\
1-year review & 12 & 14 & & 24 & 17 & 90 \\
2-year review & 3 & 13 & & 27 & 20 & 110 \\
3-year review & 4 & &
\end{tabular}

The number of occlusal surfaces that need to be treated with Ketac-bond to prevent one carious occlusal surface at 3 years is eight [ $95 \%$ confidence interval $(\mathrm{Cl}), 5-18]$, and is six $(95 \% \mathrm{Cl}, 5-10)$ for Vitremer.

\section{Commentary}

Fissure sealants are commonly used for preventing occlusal caries in permanent molars: the methods for and outcomes of sealing teeth with a resin-based sealant are well-established. ${ }^{1}$ Use of glassionomer-based sealants is less common and there is evidence indicating that retention rates and caries-preventive efficacy of these materials are far inferior to resin-based sealants. ${ }^{2,3}$ It is unfortunate therefore that the authors chose to compare a resinmodified sealant with a conventional glass-ionomer. It would have been more appropriate to use the gold standard, a resin-based sealant, as the control.

There are instances where glass-ionomer sealants are indicated, eg, in the field, where dental equipment is not available, or in patients who cannot co-operate sufficiently for a resin-based sealant to be used. These issues were not addressed in this paper.

The main aim was clearly focused and a RCT design was used with a control group (no treatment) and experimental group (conventional and resin-modified glass-ionomer, split mouth design). No mention was made of whether or not subjects or assessors were blinded, although in a study of this nature, where the placebo group has no treatment, this is difficult. Examiners were calibrated for variation, kappa values indicating that there was good agreement between examiners and between the assessments made over time by each examiner. The power calculation was not described, however. The number of dropouts at each examination interval was described but the reasons for lack of attendance were not given. No measures of variability (such as median or interquartile range) were reported. In addition, actual $P$ values were not reported for differences in caries incidence $(P=0.05$ was used) although they were given for retention rates. This suggests that the statistical significance for differences in caries incidence may have been borderline.

Retention rates were poor, although the resin-modified sealant (Vitremer) did have significantly higher retention rates than the conventional glass-ionomer (Ketac-Bond) $(P<0.001)$. Neither compare favourably to values reported for resin-based sealants in other studies, where retention rates in excess of $90 \%$ are common. ${ }^{2,3}$ Use of glass-ionomer sealants resulted in a significant reduction $(P=0.05)$ in caries incidence compared to the control group. Results from other studies, however, suggest that the reduction in caries incidence would have been greater if a resin-based sealant had been used. $^{2,3}$ There were no significant differences in caries preventive efficacy between the two types of glass-ionomer.

\section{Practice points}

- Resin-modified glass-ionomer (Vitremer) appears to have a better retention rate than conventional glass-ionomer (Ketac Bond) when used as a fissure sealant but there was no significant difference between the two in caries prevention.

- Glass ionomer sealant has a caries-preventive effect.

- A conventional resin-based sealant remains the material of choice.

Paul Ashley

Department of Paediatric Dentistry, Eastman Dental Institute for Oral Health Care Sciences, London, UK

1. Rozier G. Effectiveness of methods used by dental professionals for the primary prevention of dental caries. J Dent Educ 2001; 65:1063-1072.

2. Poulsen S, Beiruti N, Sadat N. A comparison of retention and the effect on caries of fissure sealing with a glass-ionomer and a resin-based sealant. Community Dent Oral Epidemiol 2001; 29:298-301.

3. Raadal M, Utkilen $A B$, Nilsen $O L$. Fissure sealing with a light-cured resin-reinforced glass-ionomer cement (Vitrebond) compared with a resin sealant. Int J Paediatr Dent 1996; 6:235-239.

Evidence-Based Dentistry (2003) 4, 79.

doi:10.1038/sj.ebd.6400225
Address for correspondence: Dr AC Pereira, Department of Community Dentistry School of Dentistry, University of Campinas, Piracicaba, Sao Paulo, Brazil. E-mail: apereira@fop.unicamp.br. 